\title{
Uma carta de Gabriel Harvey a Edmund Spenser
}

\author{
Lavinia Silvares Fiorussi
}

Gabriel Harvey (1545?-1630), hoje pouco conhecido, é uma das figuras mais interessantes do círculo dos engenhosos elisabetanos: travou batalhas satíricas com Thomas Nashe e Robert Green, em imitação a invectivas italianas e espanholas; advogou em favor do hexâmetro em inglês, combatendo a "vulgaridade" da rima; suscitou reações diversas a seu estilo de ciceroniano purista (o qual depois abandonaria); granjeou a amizade de Edmund Spenser, Sir Philip Sidney, do conde de Leicester, e da própria rainha Elisabeth; foi alvo de uma peça encenada por colegas de Cambridge, em que se vituperava violentamente sua auctoritas de maior discreto; anotou copiosamente os livros que possuía, registrando eventos da corte, julgando a poesia contemporânea de italianos, espanhóis, franceses, ingleses; lecionou retórica e grego na Universidade de Oxford; introduziu a lógica de Petrus Ramus em Cambridge; e há quem diga que Shakespeare o tomou por modelo para um afetado personagem de Loves Labours Lost.

A carta que se apresenta a seguir, dirigida a Spenser (apelidado por Harvey de Mestre Immerito), publicou-se pela primeira vez em 1580, num conjunto intitulado Três dignas e engenhosas Cartas familiares, trocadas entre dois homens da Universidade: em que se trata do Terremoto ocorrido em abril passado e de nossa Versificação inglesa refor- 
mada. Harvey principia referindo a sua carta anterior, na qual dava uma divertidíssima pseudo-explicação das causas do terremoto, traduzindo em afetação satírica o que se dizia nas aulas de filosofia natural de Cambridge. Depois, passa a considerar uma tópica central de discussão na época: a tentativa de se fazerem versos quantitativos em inglês, isto é, em imitação aos hexâmetros latinos. Veja-se o exemplo dos dois primeiros versos de Encomium Lauri, um dos poemas em hexâmetros que Harvey submete ao julgamento de Spenser:

What might I call this Tree? A Laurell? O bonny Laurell:

Needes to thy bowes will I bow this knee, and vayle my bonetto.

Embora a experiência tenha sido prontamente abandonada por carência de aplausos e incentivo, o debate que suscita em torno dos regramentos necessários a uma poesia vernacular em plena ascensão é fecundo, e põe em evidência as bases sobre as quais a poesia inglesa tem se apoiado desde então. Questões como a uniformização da ortografia (coisa que inexistia numa época em que as escolas de gramática cuidavam exclusivamente do ensino de latim), a eleição de modelos a serem imitados (sobretudo os antigos, mas também os contemporâneos) e a invenção de um discurso que autorizasse a poesia inglesa vernacular (para esse efeito, Harvey, sem tanta modéstia afetada, coloca-se ao lado de Homero e Ênio) entre outras, são centrais para Harvey - e aparecem, embora sucintamente, registradas nesse texto. Por fim, é de se admirar também o próprio aspecto da composição da carta, que seguindo preceitos difundidos para o gênero epistolar, nos oferece um belo exemplo de uma narratio retoricamente regrada. Para o leitor de hoje é de fato um desafio decifrar a sintaxe "amarrada" de Harvey, com seus longos períodos, sua estrutura de disseminação e recolha dos referentes. Sem querer privar o leitor dessa aventura lingüística, escolhemos fazer uma tradução que preservasse, na medida do possível, a elocução do original. 


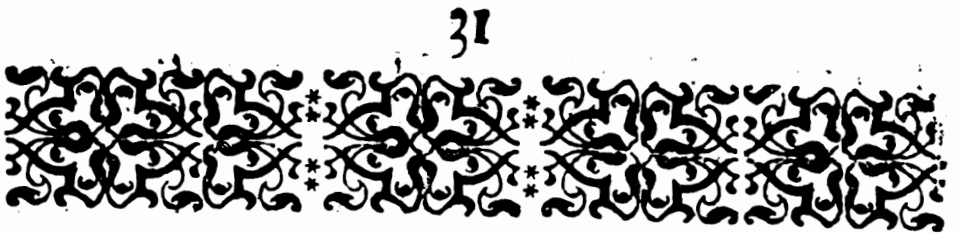

A Gallant familiar Letter, containing an Anfvere to that of M. Immerito, vvith fundry proper examples, and fome Precepts of our Englifie reformed Verfifying.

To my very fricnd A1. Immerizo.

Ignor Immerito, fo patre onet voure

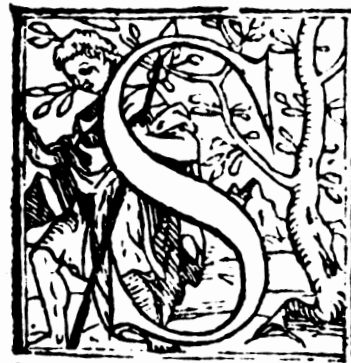
mádeleffe complaint, loptb tt, icficese of your picamble(foz of $\mathfrak{q}$ Eartliquake 3 piefuppofe you baue ere tbis receps. aro my gomole oifcourfe) and lwithall to Ict mp laforiglitige lacrametres goe as ligbere as thep came : 3 rannot chore, but tbanke ano bonont the gob sangell, (wbether it were Gabrell os come otber) that put fogmo a motion into the beaos of thofe two extellent $\mathbb{G}$ cntlemen M.Sidney, ano M.Dyer, the two berp Diamonocs of bir 9 aieftics Courte foz mano fpeclall ano rare gnalities: as to belpe fozloaroc oue ncto faincus en, terpzife foz the exchanging of 13 arbarous ano 23 alcutuin 3apmes woth Artificial therfes : the onc being in manner of pure ano fine bouloe, the other but counterfet, and bafe yle fauoured Copper. J boubt not but thetr liuelic erample, ano Poatife, wil preuaile a thoufano times mose in thost fpace, than the ocad aouerticment, ano perfuafoul of M.Afcham to the fame Effecte : wbofe Scholemaifter notwithuanting Treuctence in reiprat of fo learneo a sotiue. 3 looulo glad, ly be acquainteo with M. Drants biofoope, ano befirche you, comunenbe me to goo M.Ssduej's fuogement, ano gentlo 
Lavinia Silvares Fiorussi. Uma carta de Gabriel Harvey a Edmund Spenser

Uma Carta Galante e familiar, contendo uma Resposta à de Mestre Immerito, com muitos exemplos dignos de se saberem e alguns Preceitos de nossa reformada Versificação inglesa. ${ }^{1}$

\section{A meu grande amigo Sr. Immerito.}

Signor Immerito, para atender a tua desnecessária queixa, do resíduo de teu preâmbulo (pois do Terremoto suponho que já tenhas a esta hora recebido meu aprazível discurso), assim deixo aqui que se vão meus derradeiros hexâmetros em inglês tão levemente quanto a mim vieram: não tenho escolha senão agradecer ao bom Anjo (seja Gabriel ou algum outro) que meteu tão boa inclinação na mente daqueles dois excelentes senhores, Sr. Sidney e Sr. Dyer, os dois reais Diamantes da corte de Sua Majestade por diversas e raras qualidades: por ajudarem a levar adiante nossa nova e famosa empresa de trocar o Balductum da Rima Bárbara ${ }^{2}$ pelo Verso Artificial: este sendo em si feito do mais puro e fino Ouro, aquela nada além de reles falsificação, um ordinário Cobre feio. Não duvido de que seus vigorosos exemplos e prática farão surtir mil outros em pouco tempo, de tal modo mais frutíferos que a morta Advertência e persuasão de Mestre Ascham para o mesmo fim: cujo Scholemaister no entanto reverencio em respeito a tão discreta motivação. ${ }^{3}$ Estimaria conhecer a Prosodye do Sr. Drant, e peço-te recomende-me ao bom juízo do Sr. Sidney e às gentis Observações de Sr. Immerito. Espero que tuas próximas Cartas, as quais diariamente aguardo, tragam a mim maior amizade e convivência com todos os três. Meus próprios

A tradução dessa carta foi feita a partir de um fac-símile da primeira edição, de 1580.

Balductum: discurso confuso, desordenado.

O Scholemaister (Mestre-escola, publicado em 1571) de Roger Ascham é uma preceptiva escolar, na qual constam um currículo de autores gregos e latinos de leitura obrigatória, exercícios de composição, etc. Harvey refere-se à sentença proferida por Ascham de que a rima vernacular é coisa vulgar, indigna da poesia mais culta. 
Preceitos e Regras de Arte, creio, não devem resultar demasiado repugnantes, embora possivelmente algo distintos: e ainda não me sinto de tal modo resoluto, mas contente em reservar-me a cópia e publicação deles até que tenha cá refletido um pouco mais com meus botões e obtido conselhos adicionais por parte de Madame Sperienza. Por ora, toma isto como uma advertência geral, e dize que depositei em ti um grande mistério: sou de opinião de que não há caminho mais regular e justificável, tanto particular quanto genericamente, para a acertada e infalível Prosódia Inglesa Artificial, do que moldar nossa Língua pela Arte e forjar uma Gramática ou Retórica para ela: antes de tudo devemos concordar em uma única e própria Ortografia, em todo aspecto conforme e proporcional a nossa Natural Prosódia: seja talvez, a esse respeito, a de Sir Thomas Smithe a mais perfeita, como certamente deve ser tida por muito boa: ou seja então a de outro conhecedor mais profundo da matéria, ou cuja experiência seja mais larga que a de Sir Thomas, que indique pela necessária demonstração seus lugares defeituosos e realize a tarefa de rapidamente suprir suas carências, tornando-o mais absoluto. Eu mesmo não ouso seguir-lhe os passos antes de ver uma coisa ou outra, para cá e para lá, pública e autenticamente estabelecidas, como que por um Conselho geral, ou ato de Parlamento: e então porventura, caminhando sobre mais firme solo, em prol da Convivência, eu me aventure a fazer como outros fazem. Interim, crê-me, não ouso dar Preceitos ou definir uma Certa Arte Geral: mas repara porém minha ousadia, não sou tão receoso de meus Exemplos Específicos, dos quais, debruçando-se sobre eles, alguém talvez possa inferir o resto: considerando que têm sua fonte em algum lugar. Sobre o que, para dizer bem a verdade, nós Iniciantes temos o impulso, e a vantagem de nossos seguidores, que vão moldar e conformar tanto seus Exemplos quanto Preceitos de acordo com aquele precedente que de nós receberam: como sem dúvida assim também Homero ou outro em grego, e Ênio e não sei mais quem em latim, predispuseram e governaram os que a eles seguiram, tanto em quantidade de sílabas quanto em número de pés, e todo o resto: seus Exemplos, unicamente, 
serviam de moeda corrente, e ocupavam o lugar das Leis e das Regras para a posteridade. Tanto que foram tidos por garantia suficiente (como é ainda o caso em nossas escolas regulares de gramática) para tornar tí em tímè, e $u$ em Vnus longas, pois aquele tem tímè d'ekdios estí, e este tem Vnus homo nobis, e assim conseqüentemente no restante. ${ }^{4}$ Mas deixemos passar esse ponto sem disputa, o qual já foi tão amplamente tratado e cristalizado pelos melhores Filósofos, e nominalmente por Aristóteles, que nos aponta, como que com o dedo indicador, as fontes mesmas e principais nascentes das Artes e dos preceitos Artificiais, nas Analíticas e Metafísicas: de modo mais excelentemente definido nestes quatro Termos de Ouro, os mais célebres termos contidos em toda Lógica e Filosofia, empeiría, historia, áisthesis, epagogè: devo a propósito enviar-te um presente de AnoNovo em abril: e, como se fosse, apresentar-te um arranjo natalino já passada a Páscoa? ${ }^{5}$ Fosse a maneira de tal modo fina como a matéria é digna, eu presumiria um outro tipo de Plaudite e Gramercie ${ }^{6}$ que não este que suponho agora: mas assim sendo, rogo-te deixar de lado a parcialidade e dizer-me a tua opinião.

Agradeço aos professores Marcelo Vieira Fernandes e Marcos Martinho dos Santos por me ajudarem a "decifrar" o grego manuscrito de Harvey, quase ilegível em alguns pontos.

5 Harvey refere-se aqui aos versos em hexâmetro que copia em seguida, os quais foram compostos em dezembro e janeiro.

6 Com sentido de "aplaudam e eu agradeço". 